\title{
IUFOST2006/994 \\ Coupling airflow and heat transfer during food cooling process and refrigerated equipment
}

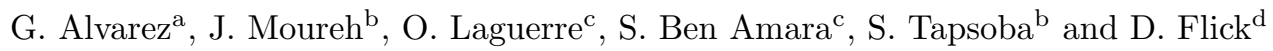 \\ ${ }^{a}$ Cemagref Unité GPAN, Parc de Tourvoie, 92163 Antony, France \\ ${ }^{\mathrm{b}}$ INRA - CEMAGREF - ENSIA - INA PG- Joint research Unit: Food Process Engineering, Cemagref \\ Antony, Parc de Tourvoie, 92163 Antony, France \\ ${ }^{\mathrm{c}}$ Cemagref, unité de recherche Génie des procédés, Parc de Tourvoie, BP. 44, 92163 Antony cedex, France \\ ${ }^{\mathrm{d} I n s t i t u t ~ N a t i o n a l ~ A g r o n o m i q u e ~ P a r i s-G r i g n o n, ~} 16$ rue Claude Bernard, 75005 Paris, France \\ graciela.alvarez@cemagref.fr
}

The quality and the safety of food products depends on their history time-temperature associated to their transformation or degradation kinetics followed during any cooling process or storage in a refrigerated equipment. This history depends on heat and mass transfer that are intimately related to airflow around the products. We are interested on cooling process applied to solids foods, treated by a fluid vector, for example airflow and heat transfer inside macro porous media (stacks of products), refrigerated cavities and some examples are cold chambers, wind tunnels, trucks (temperature controlled), domestic refrigerators, and display cabinets. We are facing a social safety challenge because of the sanitary risk is intimately related to poor management of temperature during cold chain. Quality losses are related to the heterogeneity of refrigerated treatments generating critical points risk points in a food stack. This paper shows how a better knowledge of coupling airflow heat transfer during food cooling process allows to predict temperature abuse during cold chain. Each step of cold chain is concerned: during processing of products inside pallets we apply our macro porous approach to study the flow and heat transfer heterogeneity, throughout logistic circuits abuse temperature could be observed and modeled, during refrigerated transport of products inside trucks we are able to simulate air flow and temperature distribution using CFD approach. New technologies have been developed and applied to display cabinets. We study the effect of mist chilling on the temperature control and finally we study also natural convection inside domestic refrigerators.

References

1. Alvarez G., Bournet P.E., Flick D.,(2003) "Two-dimensional simulation of turbulent flow and transfer through stacked spheres", International Journal of Heat and Mass Transfer, Volume 46, Issue 13, Pages $2459-24692$.

2. Alvarez G., D. Flick, (1999) Analysis of heterogeneous cooling of agricultural products inside bins. Part II : thermal study. J.Food Engineering, 39 239-245.

3. Darbouret M., Moureh J., Letang G., Boisson H., Alvarez G. (2004) "Study of the flow and heat transfer in a wall jet carrying droplets. Mist-Flow in refrigerated display cabinets" International Conference of Engineering and Food ICEF 9 Montpellier 7-11.March.

4. Benamara S., Flick D., Alvarez G., Moureh J. , Laguerre O.(2003) "Heat transfer and air flow in Domestic refrigerators" 21th International Congress of Refrigeration Washington 17-22 Août . 